\title{
A READEQUAÇÃO DAS ATIVIDADES DO RAMO ESTUDANTIL IEEE UFJF MEDIANTE DISTANCIAMENTO SOCIAL EM FAVOR AO SEU ESTIMADO VALOR PARA A SOCIEDADE E SEUS VOLUNTÁRIOS
}

DOI: 10.37702/2175-957X.COBENGE.2021.3591

Dalila Marques Affonso - dalila.marques@engenharia.ufff.br

Universidade Federal de Juiz de Fora

Rua João Rodrigues Vieira 17

36036-530 - Juiz de Fora - MG

Mariana Larissa Antunes da Costa - mariana.antunes@engenharia.ufjf.br

Universidade Federal de Juiz de Fora

Praca do Cruzeiro 42

36016-260 - Juiz de Fora - MG

Ana Beatriz Baldow Almeida - ana.baldow@engenharia.ufjf.br

Universidade Federal de Juiz de Fora

Rua Aristóteles Braga 35

- Juiz de Fora - MG

Matheus de Oliveira Muniz - matheus.muniz@engenharia.ufjf.br

Ramo Estudantil IEEE UFJF

Rua Prefeito Luiz Penna, 540540

36039-420 - Juiz de Fora - MG

Lucas Vantuir Ribeiro Silva - lucasbabuu@gmail.com

Universidade Federal de Juiz de Fora

Rua Adolpho Kirchmaier 197

36036-630 - Juiz de Fora - MG

Luis Henrique Lopes Lima - luishenrique.lima@ufjf.edu.br

Universidade Federal de Juiz de Fora

Rua José de Castro Barbosa 84

36033-680 - Juiz de Fora - MG

Bartolomeu Henrique Lopes - bartolomeu.henrique@engenharia.ufjf.br Universidade Federal de Juiz de Fora

Rua Santa Rita 427 
36010-071 - Juiz de Fora - MG

Resumo: Este trabalho tem como finalidade expor a readequação de atividades realizadas pelo Ramo Estudantil IEEE da UFJF (Universidade Federal de Juiz de Fora) em cenário remoto durante a pandemia por Covid-19. O núcleo é considerado ramificação estudantil exemplar do Conselho Brasil do IEEE e, a fim de manter seu impacto positivo na sociedade e para seus voluntários, adaptou parte de seus projetos de cunho técnico, social e/ou educacional para o virtual, além de ter criado novas sinergias que só foram possíveis devido a aproximação causada pelas redes sociais.

Palavras-chave: Educação. STEM. Engenharias. Atividades remotas. Readequação. 


\section{A READEQUAÇÃO DAS ATIVIDADES DO RAMO ESTUDANTIL IEEE UFJF MEDIANTE DISTANCIAMENTO SOCIAL EM FAVOR AO SEU ESTIMADO VALOR PARA A SOCIEDADE E SEUS VOLUNTÁRIOS}

\section{INTRODUÇÃO}

Os efeitos da pandemia por Covid-19, doença advinda do Sar-Cov-2, popularmente conhecido como coronavírus 2020 , foram visíveis em vários setores, seja na saúde pública quanto na economia (Oliveira e Souza, 2020). Na tentativa de evitar a proliferação do vírus causador da tal doença e diminuir a exposição a riscos, grande parte dos países interromperam as atividades presenciais em instituições educacionais, provocando, de acordo com a ONU (Organização das Nações Unidas), impacto em mais de $70 \%$ da população estudantil do mundo (ONU, 2020). Por esse motivo, a forma como a maioria das atividades escolares era desenvolvida se tornou incompatível nesse novo cenário, e, diante disso, projetos e iniciativas tanto das universidades quanto de organizações estudantis precisaram ser adaptados. Uma dessas organizações que precisou urgentemente adequar suas atividades nesse novo cenário é o Ramo Estudantil IEEE UFJF, segmentação estudantil do Instituto de Engenheiros Eletricistas e Eletrônicos (IEEE), a maior organização mundial com interesses em tecnologias a favor do desenvolvimento da humanidade.

O presente trabalho tem como objetivo apresentar as estratégias utilizadas pelo Ramo Estudantil IEEE UFJF para a readequação de suas atividades perante o momento de distanciamento social. É fato que o núcleo precisou se reinventar e esse foi um grande desafio mediante a um cenário que a população ainda enfrenta. Devido essa necessidade, todas as atividades presenciais foram suspensas, obrigando os membros a usar de sua criatividade e resiliência para continuar o desenvolvimento dos projetos, que estão ligados a diversos Objetivos de Desenvolvimento Sustentável (ODSs) da ONU, como 04 Educação de Qualidade, 5 - Igualdade de Gênero, 10 - Redução das Desigualdades e 17 Parcerias e Meios de Implementação (Nações Unidas Brasil, 2021). As atitudes tomadas e as estratégias adotadas permitiram a continuidade do desenvolvimento acadêmico dos voluntários no âmbito da pesquisa e extensão, mesmo durante o período de suspensão das atividades na universidade.

O trabalho inicia com uma breve descrição sobre o IEEE e o Ramo Estudantil IEEE UFJF. Posteriormente é apresentada as atividades do núcleo, sejam aquelas que tiveram que ser adaptadas quanto aquelas que só foram possíveis pelo cenário remoto. Por fim, serão apresentados os impactos das atividades do núcleo tanto nos voluntários quanto na sociedade a qual interage com os projetos desenvolvidos pelos estudantes.

\section{2 \\ O INSTITUTO DE ENGENHEIROS ELETRICISTAS E ELETRÔNICOS}

A organização sem fins lucrativos denominada IEEE, Institute of Electrical and Electronics Engineers, em português Instituto de Engenheiros Eletricistas e Eletrônicos, é a maior organização técnica profissional do mundo voltada para a inovação tecnológica e excelência para o benefício da humanidade. De acordo com o último relatório anual, de 2019, atualmente possui mais de 419 mil membros.

O IEEE é dividido em 10 regiões no mundo, cada região é dividida em Seções (Sections) ou Conselhos (Councils), dependendo do país. No caso do Brasil, como pode ser visto na Figura 1, existe o Conselho Brasil, o qual possui 5 Seções, a saber: Minas Gerais, Rio de Janeiro, Centro-Norte Brasil, Nordeste Brasil e Sul Brasil. 
Figura 1 - Seções do IEEE no Brasil

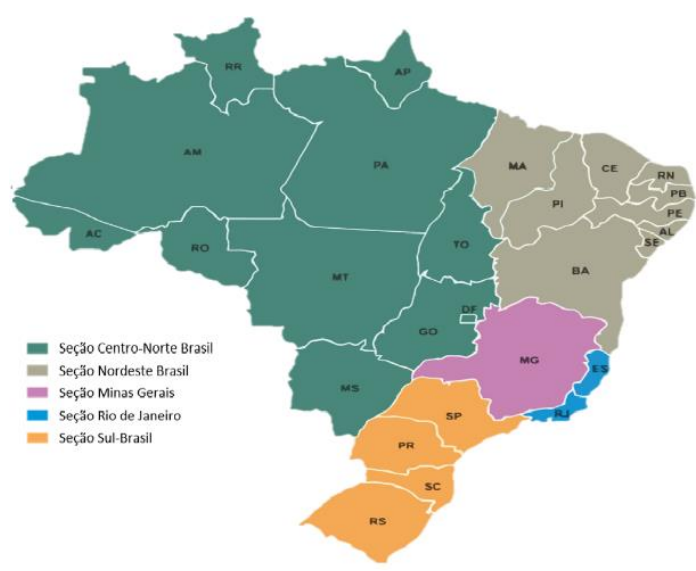

Fonte: IEEE - Conselho Brasil 2021

Os ramos estudantis (Students Branches), categoria o qual IEEE UFJF pertence, são filiais estudantis submetidas às seções. Atualmente existem cerca de 50 ramos do IEEE registrados no Conselho Brasil, mas, por ora, não é possível mensurar quais estão ativos.

\subsection{Ramo Estudantil IEEE UFJF}

O Ramo Estudantil IEEE da Universidade Federal de Juiz de Fora (UFJF) tem suas atividades e projetos de cunho educacional, técnico e/ou social, ligados ao STEM (Science, Technology, Engineering and Maths - Ciência, Tecnologia, Engenharia e Matemática), que estão atrelados aos valores do IEEE, e as áreas de interesse dos capítulos técnicos e grupos de afinidades, subgrupos do ramo estudantil (PIRES et al, 2019).

Atualmente, o núcleo conta com o Conselho Administrativo, composto por presidente, vice-presidente, secretária, tesoureiro e webmaster. Além disso, possui seis diretorias, sendo elas de Gestão de Pessoas, Qualidade, Membresias, Cursos e Eventos, Tecnologia da Informação e Marketing. Possui também quatro capítulos técnicos estudantis, a saber: IEEE PES (Sociedade de Potência e Energia), IEEE RAS (Sociedade de Robótica e Automação), IEEE CAS (Sociedade de Circuitos e Sistemas) e IEEE IAS (Sociedade de Aplicações Industriais). Por fim, possui 2 grupos de afinidade, sendo eles 0 IEEE WIE (Mulheres em Engenharia) e IEEE SIGHT (Interesses em Tecnologias Humanitárias), e um projeto de conversação em inglês, chamado Speak Your Mind.

Além dos projetos, o ramo estudantil organiza e participa de eventos, ações sociais e educativas, concursos a nível nacional e internacional e troca de experiências com outros ramos estudantis do Brasil e do mundo. O ramo IEEE UFJF tem grande foco no desenvolvimento dos membros através dos projetos e dos cargos de liderança, que possibilitam um enorme aprendizado técnico, humanitário e de gestão. Ao longo de sua trajetória, acumulou numerosos prêmios nacionais, regionais (América Latina e Caribe) e mundiais, obtendo, em 2020, o reconhecimento de ramo exemplar nacional e internacionalmente. 


\section{READEQUAÇÃO DAS ATIVIDADES DO RAMO}

O começo do ano de 2020 foi marcado pela reorganização interna do ramo estudantil, com a troca dos membros do Conselho Geral, responsável pela administração geral do ramo estudantil, e demais lideranças, e planejamento das estratégias de ação e atividades do ano recorrente. Dentre as diversas atividades planejadas, podemos citar como mais importante a escolha de Juiz de Fora/MG como cidade sede da renomada Reunião Nacional de Ramos e Reunião Nacional de Young Professionals 2020 (RNR \& RNYP 2020), grande evento de exímia importância para os ramos estudantis do IEEE brasileiros. A organização do evento foi suspensa por tempo indeterminado com o advento da pandemia de COVID-19, que impossibilitou a realização futura do encontro.

Diversas outras atividades do ramo estudantil também foram suspensas por um período de incertezas diante da situação crítica em que se encontravam, até que os líderes e demais voluntários conseguissem se adequar à nova rotina e dinâmica de distanciamento social e, consequentemente, adaptar também os projetos em andamento. Muitos projetos, por terem maior cunho técnico e atividades práticas a serem desenvolvidas para obter resultados efetivos, não puderam ser encaixados nos formatos à disposição e tiveram as atividades interrompidas. Já outros, no entanto, se adaptaram perfeitamente à nova proposta, totalmente online, e recorreram às mais criativas ferramentas tecnológicas e estratégias para alcançar seus objetivos. Houve, ainda, novas atividades que só foram possíveis sob essas circunstâncias.

A readequação da rotina do ramo estudantil para o trabalho remoto se deu gradualmente, com estudos de caso para introduzir, aos poucos, novas tecnologias e instrumentos. As plataformas online oferecidas gratuitamente foram amplamente utilizadas para manter a atividade do núcleo durante a pandemia: reuniões, tanto internas quanto gerais, e outras atividades que requerem maior dinâmica e interação de uma videoconferência, foram realizadas através do serviço Google Meet; o Google Agenda também foi de grande importância para manter o calendário de atividades e eventos do grupo atualizado e organizado, além dos recursos vinculados ao Google Meet que tornaram ainda mais dinâmica a comunicação entre os membros; a plataforma Trello, já utilizada antes deste período de distanciamento social, teve um papel de suma importância no planejamento interno de projetos e demais atividades, auxiliando na organização, delegação de atividades, controle de prazos e acompanhamento de progresso.

\subsection{Atividades adaptadas ao Home Office}

Atrelado a readequação do ramo em si, os projetos desenvolvidos pelos núcleos também sofreram adaptações, onde o propósito e o desafio não era apenas de se adaptar ao novo cenário de distanciamento social, mas também adaptar as atividades de forma que a entrega final fosse tão satisfatória como antes em situações comuns.

O projeto IEEEscolas, que originalmente era desenvolvido presencialmente, sofreu diversas mudanças para a sua execução remota. Em resumo, o objetivo do projeto é levar o conhecimento prático de ciências para as escolas que não possuem um laboratório de ciências estruturado, a fim de disseminar o aprendizado àqueles que não possuem tal acesso. São abordados temas como ciências básicas, robótica e energias renováveis, ações promovidas em integração com os subnúcleos IEEE PES, IEEE RAS, IEEE SIGHT e IEEE WIE da UFJF. Dado o desafio, a adaptação da atividade era extremamente necessária, visto também que a continuidade do projeto poderia estimular e incentivar os alunos das escolas parceiras aos estudos no modelo home office. Sendo assim, como visto na Figura 2, a principal ferramenta utilizada foi o Instagram, em que os integrantes criaram 
uma conta exclusiva para o projeto, onde foram feitas diversas publicações entre fotos e vídeos, como explicações de experimentos, apresentação dos módulos do projeto e dicas de atividades educativas para exercitar durante a quarentena.

Figura 2 - Projeto IEEEscolas e a rede social do projeto

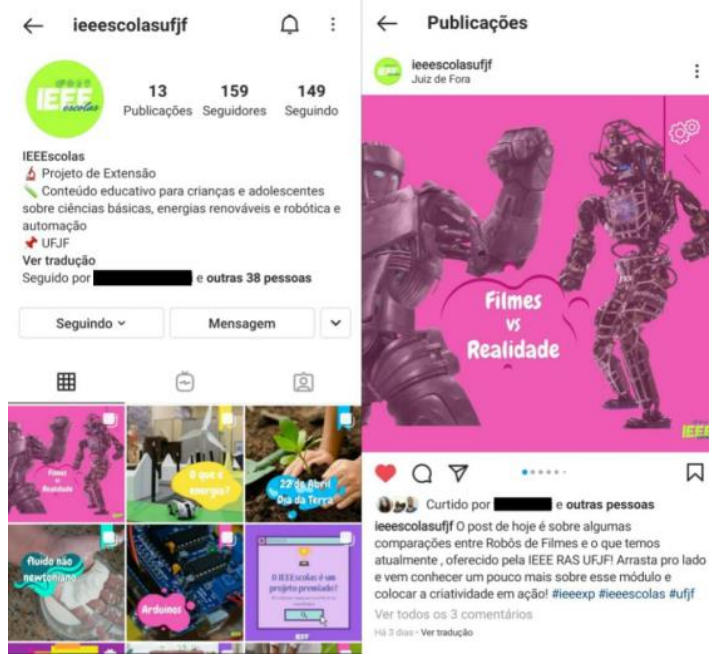

Fonte: Próprio autor 2021

Outra atividade a passar por adaptações foi, como visto na Figura 3, o Mutirão Tecnológico, projeto desenvolvido pelo IEEE WIE UFJF, que tem como missão levar conhecimentos interligados à engenharia elétrica, construção civil e tecnologia para as mulheres, de forma a colaborar com o empoderamento e independência das mulheres. Assim como a grande parte dos projetos do ramo, o Mutirão Tecnológico era um projeto presencial que passou por reformulações para atender suas necessidades de forma remota. A fim de se readequar, as voluntárias desenvolveram para o projeto cartilhas abordando assuntos como: interpretação da fatura de energia elétrica, finanças para mulheres, violência doméstica, eletricidade residencial, segurança na internet e tutoriais sobre celulares. Além disso, também trabalhou com lives pelo Instagram, que é uma ferramenta que o grupo usa muito bem, e teve maior engajamento durante a pandemia. Foram realizadas duas lives, com os temas: "Violência de Gênero no Ambiente Acadêmico" e "Usucapião como instrumento para levar propriedade de terras às mulheres". E por último, o grupo promoveu um workshop integrado à III Semana das Mulheres do IEEE WIE UFJF ministrado por uma voluntária do ramo, ensinando a confeccionar uma extensão elétrica. 
Figura 3 - Projeto Mutirão Tecnológico

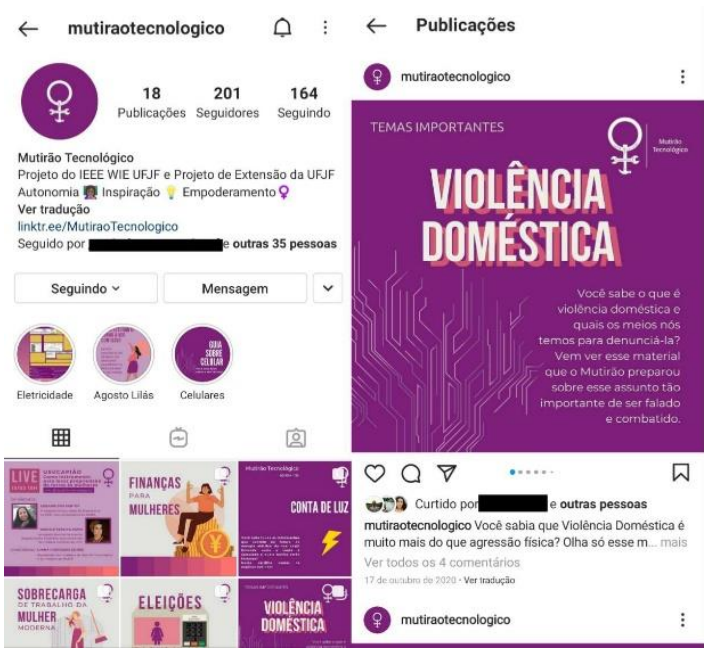

Fonte: Próprio autor 2021

O projeto Conversando com as Mãos, desenvolvido pelo IEEE WIE UFJF, também passou por mudanças, adaptando-se às restrições impostas pela quarentena. $O$ projeto consiste em oficinas para a prática de LIBRAS (Língua Brasileira de Sinais) à comunidade interna da UFJF, aproximando a sociedade ouvinte à realidade daqueles que sempre tiveram que se adaptar. Em meio às adversidades, os voluntários elaboraram uma nova metodologia para a continuidade do projeto, realizando encontros quinzenais online, por vezes ministrados pelos voluntários, outrora ministrados por membros da comunidade surda da UFJF que participavam das atividades.

Além dos projetos, a preocupação do Ramo Estudantil IEEE UFJF com o bem-estar dos seus membros em meio ao caos da pandemia se elevou. A saúde mental, mesmo antes da pandemia, sempre foi pauta na elaboração das atividades, e com o isolamento social a ênfase nesse assunto se tornou primordial para o bom andamento da instituição. Para manter os membros engajados e mais próximos, o ramo realizou e realiza encontros online, a fim de criar uma interação confortável entre membro e instituição. As atividades mais comuns relacionadas à integração são os jogos online. Alguns exemplos de jogos são o Gartic, jogo online em que é preciso descobrir o nome do desenho que a outra pessoa está fazendo, e o StopotS, uma adedanha virtual.

Durante tal período, o Ramo Estudantil IEEE UFJF buscou manter o contato com os seus integrantes através de reuniões periódicas, a fim de manter os voluntários engajados e informados sobre o prosseguimento das atividades. De forma remota, todo mês foram realizadas as seguintes reuniões promovidas pelos membros do conselho geral da instituição: Reunião Geral, com a participação de todos os voluntários, Reunião de Presidentes, nas quais apenas os presidentes dos capítulos técnicos e grupos de afinidade necessitam participar, e a Reunião de Diretores, as quais apenas aqueles em cargos de diretoria precisam estar presentes. As reuniões têm duração aproximada de uma hora, evitando o prolongamento e, consequentemente, a fadiga dos membros. Além disso, os membros do Conselho Geral promovem, esporadicamente, pequenas integrações, como dinâmicas de check-in, tanto para atuar como um quebra gelo quanto para suavizar o impacto, transformando esses momentos em algo mais confortável. Além disso, para trazer ainda mais para perto os voluntários, no final de cada Reunião Geral é enviado um formulário online, por meio do Formulários Google, apelidado pelo grupo de "Forte Abraço", no qual os voluntários o preenchem com elogios, felicitações e boas energias entre si. 
No mês de julho de 2020, houve a realização pela primeira vez da RNR (Reunião Nacional de Ramos Estudantis), o maior congresso nacional do IEEE no Brasil, de maneira remota. $O$ evento foi durante um final de semana com várias palestras sobre vantagens de ser um membro IEEE. Um voluntário que já foi presidente do Ramo Estudantil IEEE UFJF participou ativamente da organização do evento, devido à sua experiência no assunto. Além disso, um grande marco desse evento são os Concursos de Casos de Sucesso, no qual cada ramo estudantil pode submeter seus projetos realizados durante o período estipulado através de editais. Ele é dividido em diversas categorias e na edição de 2020 o núcleo da UFJF conquistou 12 prêmios, entre eles o de Ramo Exemplar do Conselho Brasil.

Já no mês de novembro ocorreu a SBRM (Student Branch Regional Meeting - Reunião Regional de Membros). Esse evento é bastante similar ao citado anteriormente, porém de nível internacional, uma vez que, além de ramos estudantis no Brasil, estavam presentes ramos de outros países da América Latina e Caribe, contendo palestras em sua maioria em inglês. Como no evento anterior, o núcleo da UFJF marcou presença dos concursos e obteve, coincidentemente, 12 prêmios, dentre eles o de Ramo Estudantil Exemplar, desta vez a nível regional.

Em relação às atividades humanitárias, o Ramo Estudantil IEEE UFJF colaborou com a arrecadação de alimentos, livros e brinquedos para um projeto de extensão da Faculdade de Engenharia da UFJF, que trabalha usando a ciência como forma de redução da desigualdade. Durante a pandemia, esse projeto que possui um valor de entrega alto ao ir de encontro a comunidades carentes e socialmente distantes da experiência universitária, levando conhecimentos sobre ciências em geral, precisou ser adaptado. Uma das formas conseguidas para manter algum impacto, principalmente pela limitação do acesso efetivo à internet dessas pessoas, desenvolveu tais campanhas e o núcleo da UFJF utilizou do poder de suas redes sociais para colaborar ativamente com a iniciativa.

Os projetos técnicos do grupo, em geral, foram incapazes de dar continuidade às atividades de maneira remota, visto que para muitos eram necessários os materiais físicos como arduinos, furadeira de bancada, ferramentas de uso geral como alicates e cabos, e tais elementos ficaram no espaço físico do Ramo Estudantil IEEE UFJF na referida universidade, na qual os voluntários não tiveram acesso desde o dia 17 de março de 2020. Devido a isso, os capítulos RAS e CAS procuraram uma maneira diferente de mobilizar seus membros. Dessa forma eles montaram minicursos de softwares como Protheus e Tinkercad para a capacitação dos voluntários, de modo que quando as atividades presenciais retornarem os capítulos podem retomar seus projetos. O núcleo IEEE WIE UFJF realiza, em todo mês de março, a atividade Semana das Mulheres. A terceira edição, em 2021, foi realizada de forma remota. Foi uma semana com atividades de relaxamento, palestras sobre saúde das mulheres, treinamentos e workshops, além de um momento em que os participantes puderam cozinhar com uma chef renomada. A transmissão foi feita via o software open source OBS (Open Broadcaster Software) para o canal do YouTube do grupo e contou com um total de 155 inscritos.

\subsection{Atividades Oriundas do Distanciamento Social}

Algumas atividades só puderam ser realizadas devido ao aumento do uso de plataformas virtuais para encontros, como Google Meet, Zoom e afins. Como realizar atividades de forma remota não fazia parte da cultura do Ramo Estudantil IEEE UFJF, foi uma novidade e os voluntários utilizaram-se delas para continuar e melhorar seu poder de impacto.

O evento "Hackahome: Do IEEE UFJF para o IEEE Brasil" foi um concurso promovido pelo Ramo Estudantil IEEE UFJF, seguindo os moldes de uma maratona de estruturação e planejamento de projetos home office, construídos em equipes ao longo de 
uma semana. Os projetos podiam ser de cunho educacional, técnico, humanitário ou de gestão. O objetivo era fomentar a geração de ideias de projetos e atividades que os ramos Estudantis IEEE do Conselho Brasil pudessem realizar durante o período de isolamento social, e colaborar para que os ramos estudantis de todo o país se mantivessem ativos, inclusive com mentorias de pessoas de outros estados.

Durante o ano de 2020, foram realizadas atividades para o público interno e externo ao grupo, com temas diversos, de cunho técnico, humanitário ou educacional. Logo no início da pandemia, foi realizado um workshop com uma psicóloga parceira do grupo sobre saúde mental, um tema extremamente necessário no período descrito. Foi realizada também uma palestra sobre a dor emocional com um especialista no tema. Além disso, foram realizados webinars do capítulo técnico IEEE PES UFJF, em parceria com a Seção Minas Gerais, o qual gerou networking entre voluntários e empresas. Em junho, devido ao mês do Orgulho LGBT, em parceria com o Ramo Estudantil IEEE UFPA, a Mesa do Orgulho LGBT, com diversos voluntários e voluntárias de todo Brasil. Além disso, foi elaborada uma live, via Instagram, sobre Direitos das Mulheres, em parceria com uma graduanda em Direito pela UFJF e, o dia da Consciência Negra foi comemorado com outra live, com Carla Sena, uma engenheira eletricista para falar sobre mercado de trabalho.

A Semana de Engenharia e Tecnologia do Ramo Estudantil IEEE UFJF (SET-IEEE) foi desenvolvida no final de setembro e início de outubro de $2020 \mathrm{com}$ uma programação focada para a preparação no mercado de trabalho na área de engenharia e correlatas nos participantes, sendo totalmente gratuito. Dois pontos fortes do evento foi que $75 \%$ das palestrantes eram mulheres discursando sobre o trabalho exercido por elas, e não pelas dificuldades encontradas pelas tais, e a participação da presidente mundial do IEEE na época, norte americana. Pelo fato dessa atividade ter sido feita em inglês, contou-se com uma tradução simultânea, patrocinada pela Seção Minas Gerais. O projeto Meninas Super Engenheiras também foi outro destaque dentro do referido ano, o título faz alusão ao desenho animado "As Meninas Superpoderosas". O evento consistiu em duas lives pelo YouTube com meninas graduandas nas engenharias da UFJF e um vídeo, postado no Instagram do IEEE WIE UFJF, sobre as diferenças entre os cursos de engenharia civil nas universidades federais mineiras. Seu grande diferencial foi ter atingido um novo público, o de pré-vestibulandas, e ter recebido escolas da cidade sede e região.

A iniciativa LiWie, projeto desenvolvido pelos grupos de afinidade IEEE WIE da UFJF, Universidade Federal de São João del-Rey (UFSJ) e pela Universidade Estadual Paulista (UNESP) de Guaratinguetá, teve por objetivo catalogar e reunir todos os núcleos WIEs ativos do Brasil, algo nunca feito antes pela distância regional. No total foram 17 unidades participantes, divididas em 3 lives, com participação média de 50 pessoas em cada uma, e com a finalização com uma palestra da Presidente do Conselho Brasil do IEEE do respectivo ano. Já em 2021, o foco da nova gestão foi definido como o desenvolvimento interpessoal dos voluntários. Para tal, foi feito um calendário de eventos, palestras e workshops, para o desenvolvimento de softskills, competências interpessoais, como inteligência emocional, liderança, negociação e oratória, e hardskills, competências técnicas, como os softwares necessários para auxiliar os futuros profissionais de engenharia. Já foram realizadas parcerias com empresas da região, como a FaçaAgora!, que possui foco em desenvolvimento de carreira e com a Hackeando Processos, especialista em vendas, para que os projetos desenvolvidos pelo Ramo Estudantil IEEE UFJF sejam melhor apresentados. Além disso, houve workshops sobre Inteligência Emocional, através de um curso gratuito do Grupo Voitto, uma escola de negócios, sobre Autoconhecimento e Produtividade Ágil com o Projeto EZ, focado em desenvolver pessoas, oratória, em parceria com o Instituto Feminino de Engenharia (IFE), e capacitações de 
Excel, Power BI, VBA e Processos Seletivos com a empresa Motim Quebre o Giz. A maioria dessas atividades foram feitas na base de parceria, com troca por divulgação.

Ainda em 2021, foi realizada uma palestra interna, exclusivamente para voluntários do grupo em questão, com a Presidente Mundial do IEEE WIE em exercício, sobre motivação e sua trajetória nos núcleos, como forma de empoderamento e representatividade para mulheres em STEM.

\section{O IMPACTO DAS ATIVIDADES DO RAMO ESTUDANTIL IEEE UFJF DURANTE O DISTANCIAMENTO SOCIAL}

Vindo de encontro aos planejamentos e expectativas da gerência do Ramo Estudantil IEEE UFJF para as atividades do ano de 2020, a pandemia da Covid-19 tornou necessário o abrupto processo de distanciamento social e uma série de outras restrições impostas a todas as esferas da sociedade. Por consequência, todas as atividades acadêmicas precisaram ser temporariamente paralisadas e, posteriormente, replanejadas.

Para o ramo estudantil as mudanças foram muitas, começando pela interdição da sala onde os projetos e reuniões de planejamento da equipe ocorrem. Além disso, fez-se necessário o adiamento do maior evento estudantil do IEEE a nível nacional a ser sediado pelo IEEE UFJF nas dependências da universidade durante o feriado de Corpus Christi daquele ano, a Reunião Nacional de Ramos Estudantis e Young Professionals (RNR \& RNYP). A exemplo do ocorrido com a RNR, uma série de visitas técnicas, das quais podese citar a excursão para o museu Nuclear de Angra dos Reis planejada para setembro, e projetos sociais como o IEEEscolas precisaram ser paralisados por tempo indeterminado. No entanto, em uma manobra de readaptação, o Conselho Administrativo do Ramo Estudantil deu início a um plano de retomada das atividades de maneira remota, apoiado no uso de tecnologias à distância, por entender que as atividades promovidas pela instituição são de suma importância para a manutenção da saúde, bem-estar e do desenvolvimento não só de seus membros e voluntários como da sociedade acadêmica e externa de modo geral.

\subsection{Nos Voluntários do Ramo Estudantil IEEE UFJF}

A completa suspensão das atividades acadêmicas da segunda quinzena de março até a primeira quinzena de setembro, somada à nova conjuntura de segregação e caos social impostos pela pandemia trouxeram consigo uma grande preocupação com a saúde física e mental da população. Não obstante, o cuidado com os colaboradores do ramo passou, mais do que nunca, a ser uma prioridade.

Logo, ao dar continuidade, de maneira virtual, às suas atividades, o IEEE UFJF contribuiu para que seus membros e voluntários se mantivessem ocupados e produtivos, reduzindo assim a carga de estresse causada pela situação. Ao se aproximar de seus colaboradores através de atividades lúdicas e descontraídas, o ramo promoveu, mesmo à distância, contato e calor humano essenciais à manutenção da boa saúde mental da equipe. Neste período, encontros como o "Bar do I3Zé", um happy hour comum após as reuniões presenciais, e reuniões gerais temáticas, como a edição "Festa Junina", contribuíram para que o ramo se mantivesse coeso.

Um outro ponto positivo verificado ocorreu com relação ao desenvolvimento das Soft Skills, principalmente no que tange às lideranças do IEEE UFJF. Os líderes, sejam de projetos, de capítulos técnicos ou de diretorias, foram obrigados a se readaptar perante as novas condições enfrentadas. O fato das atividades presenciais terem sido suspensas trouxe à tona uma série de habilidades importantes para a boa continuidade da gestão, 
dentre as quais pode-se citar a empatia, comunicação, proatividade, gestão de conflitos, inteligência emocional e muitas outras competências interpessoais vistas como essenciais ao profissional do futuro.

\subsection{Na Comunidade Acadêmica}

Uma das formas encontradas pelo IEEE UFJF para dar continuidade à sua atuação foi somar os esforços para a documentação dos seus projetos e das atividades desenvolvidas pela equipe de modo que estes pudessem ser submetidos e publicados nos mais diversos eventos, competições e concursos. Na incessante busca por eventos e atividades que venham a contribuir com seus membros, voluntários e com a sociedade como um todo, a filial estudantil do IEEE da UFJF descobriu que apesar do afastamento social as fronteiras do mundo se encontram muito mais próximas, reflexo do encurtamento das distâncias promovido pelas tecnologias. A derrubada da barreira da distância vem sendo uma das grandes aliadas do ramo durante a pandemia. Com a interação on-line, a organização vem conseguindo reunir especialistas, palestrantes, estudantes e professores dos mais diversos lugares do mundo. Um exemplo de sucesso dessa nova realidade foi a primeira edição da Semana de Engenharia e Tecnologia (SET-IEEE), evento idealizado e desenvolvido pelos membros do RE IEEE UFJF que contou com a participação da então presidente Mundial do IEEE, Susan Kathy. Em cada um dos destaques que recebeu durante esta trajetória o ramo trouxe consigo prestígio e orgulho à centenária Faculdade de Engenharia e à Universidade Federal de Juiz de Fora.

\subsection{Na Comunidade Externa}

Talvez o aspecto mais impactado pela pandemia tenha sido a interação do ramo com a comunidade externa. A proibição das atividades presenciais é uma barreira intransponível para a continuidade de muitos dos projetos sociais desenvolvidos pela instituição. No entanto, a equipe continuou os trabalhos de forma diferente e criativa visando continuar retribuindo os investimentos da sociedade na formação profissional dos alunos. Através das redes sociais de seus diversos núcleos, conteúdos de cunho educativo são divulgados no intuito de promover a aproximação da população com temas relevantes que muitas vezes são inacessíveis. Desta forma, o ramo contribui com a disseminação de boas práticas e conhecimentos relevantes tendo sempre em vista a acessibilidade e inclusão dos materiais.

\subsection{No Contexto do IEEE Brasil}

No que tange ao contexto das filiais estudantis do IEEE no Brasil, pode-se destacar algumas instituições de grande relevância histórica, dentre as quais se encontra o Ramo Estudantil IEEE da UFJF. Durante o período de incerteza provocado pela pandemia do novo coronavírus a organização se mostrou pioneira no cenário ao promover atividades de maneira remota. Ao perceber o impacto causado pela Covid-19 nas demais instituições, o IEEE UFJF não hesitou em promover atividades de interação entre ramos, como no caso do HackaHome. Além disso, a instituição se fez presente em encontros que visavam discutir soluções e ações de combate aos efeitos colaterais da pandemia, como a desmotivação de voluntários e líderes. O resultado dessa participação foi o fortalecimento das estruturas do cenário do IEEE Brasil e a maior proximidade e colaboração entre as diversas filiais estudantis do país. 


\section{Considerações finais}

Toda a instabilidade gerada em 2020 devido ao cenário da pandemia por Covid-19 trouxe muita apreensão à toda equipe do Ramo Estudantil IEEE UFJF, tanto pela questão de saúde pública quanto pela educação em si. Desde o início da pandemia o grupo vem se reinventando e fazendo com que seus voluntários tenham uma atividade extracurricular que está ajudando efetivamente a saúde mental e ainda fornecendo capacitações tão necessárias para o futuro profissional de engenharia. O grupo observou no cenário remoto uma oportunidade de desenvolver iniciativas as quais seriam provavelmente impossíveis, principalmente por questões geográficas e financeiras, em um antigo normal. Conseguir manter algumas das atividades voltadas à comunidade externa da Universidade Federal de Juiz de Fora ativa, mesmo que adaptadas, traz ao grupo um senso de responsabilidade social cumprido dentro do que era possível na situação atual.

Por fim, como maior aprendizado perante o novo normal $e$ as atividades educacionais, sejam intra ou extracurriculares, tem-se que os futuros profissionais, não só de engenharia, devem estar preparados para quaisquer tipos de instabilidade e isso só é possível com experiências além da universidade, como o trabalho feito pelo Ramo Estudantil IEEE UFJF.

\section{Agradecimentos}

Toda a equipe de voluntários do Ramo Estudantil IEEE UFJF se solidariza pelas pessoas as quais perderam suas vidas devido à pandemia. Agradecemos aos professores Luís Henrique Lopes Lima, Janaína Oliveira Gonçalves, Bruno Henriques Dias, Leonardo Willer de Oliveira e Zélia Maria da Costa Ludwig por todo apoio. Além disso, agradecemos a Faculdade de Engenharia da UFJF, a Pro Reitoria de Extensão da UFJF, a Seção Minas Gerais do IEEE e o Conselho Brasil do IEEE pelo suporte de sempre.

\section{REFERÊNCIAS}

HACKAHOME IEEE UFJF. O que é o Hackahome?. Disponível em: https://attend.ieee.org/ufjfhackahome/. Acesso em: 24 abr. 2021.

IEEE. Annual Report 2019. Disponível em: https://www.ieee.org/content/dam/ieeeorg/ieee/web/org/corporate-communications/annual-report/2019AnnualReport/2019-ieee-annualreport-final.pdf. Acesso em: 24 abr. 2021.

NAÇÕES UNIDAS BRASIL. Objetivos de Desenvolvimento Sustentáveis. Disponível em: https://brasil.un.org/pt-br/sdgs. Acesso em: 24 abr. 2021.

OLIVEIRA, H. D. V. D; SOUZA, F. S. D. Boletim de Conjuntura: DO CONTEÚDO PROGRAMÁTICO AO SISTEMA DE AVALIAÇÃO: REFLEXÕES EDUCACIONAIS EM TEMPOS DE PANDEMIA (COVID-19). 5. ed. Roraima: Revista UFRR, 2021. p. 1-12.

ONU NEWS. Covid-19: Unesco divulga 10 recomendações sobre ensino a distância devido ao novo coronavírus. Disponível em: https://news.un.org/pt/story/2020/03/1706691. Acesso em: 23 abr. 2021.

PIRES, Carlos Alexandre de Almeida et al. A importância dos trabalhos realizados pelo Ramo Estudantil IEEE UFJF na formação de voluntários e no desenvolvimento da Universidade. In: XLVII Congresso Brasileiro de Educação em Engenharia e II Simpósio Internacional de Educação em Engenharia da ABENGE, 2019, Ceará. Anais. Fortaleza, 2019. 
PRIMEIRA SEMANA DE ENGENHARIA E TECNOLOGIA DO RAMO ESTUDANTIL IEEE UFJF. Sobre o evento. Disponível em: https://attend.ieee.org/ufjf-1set/. Acesso em: 24 abr. 2021. RAMO ESTUDANTIL IEEE UFJF. O IEEE UFJF. Disponível em: < https://edu.ieee.org/br-ufff/ieeeufj/>. Acesso em: 21 abr. 2021.

TERCEIRA SEMANA DAS MULHERES. Sobre o evento. Disponível em: https://sites.google.com/engenharia.ufjf.br/iii-semana-das-mulheres/p\%C3\%A1ginainicial?authuser=0. Acesso em: 24 abr. 2021.

UFJF NOTÍCIAS. UFJF suspende atividades presenciais nesta terça mantendo somente serviços essenciais. Disponível em: https://www2.ufff.br/noticias/2020/03/16/ufjf-suspendeatividades-presenciais-nesta-terca-mantendo-somente-servicos-essenciais/. Acesso em: 24 abr. 2021.

\section{THE READJUSTMENT OF IEEE UFJF STUDENT BRANCH ACTIVITIES THROUGH SOCIAL DISTANCING IN FAVOR OF ITS ESTIMATED VALUE FOR SOCIETY AND ITS VOLUNTEERS}

Abstract: This work aims to expose the readjustment of activities carried out by the IEEE Student Branch of UFJF (Federal University of Juiz de Fora) in a remote setting during the Covid-19 pandemic. The nucleus is considered an exemplary student branch of the IEEE Brazil Council and, in order to maintain its positive impact on society and its volunteers, it adapted part of its technical, social and/or educational projects to the virtual, in addition to creating new synergies that were only possible due to the approximation caused by social networks.

Keywords: Education. STEM. Engineering. Remote activities. Readjustment. 